\title{
Optimization of Deacetylation Process for Regenerated Cellulose Hollow Fiber Membranes
}

\author{
Xuezhong He \\ Department of Chemical Engineering, Norwegian University of Science and Technology, 7491 Trondheim, Norway \\ Correspondence should be addressed to Xuezhong He; xuezhong.he@ntnu.no
}

Received 21 April 2017; Revised 16 May 2017; Accepted 1 June 2017; Published 29 June 2017

Academic Editor: Yulin Deng

Copyright (C) 2017 Xuezhong He. This is an open access article distributed under the Creative Commons Attribution License, which permits unrestricted use, distribution, and reproduction in any medium, provided the original work is properly cited.

Cellulose acetate (CA) hollow fibers were spun from a CA+ Polyvinylpyrrolidone (PVP)/N-methyl-2-pyrrolidone $(\mathrm{NMP}) / \mathrm{H}_{2} \mathrm{O}$ dope solution and regenerated by deacetylation. The complete deacetylation time of $0.5 \mathrm{~h}$ was found at a high concentration $(0.2 \mathrm{M})$ $\mathrm{NaOH}$ ethanol (96\%) solution. The reaction rate of deacetylation with $0.5 \mathrm{M} \mathrm{NaOH}$ was faster in a $50 \%$ ethanol compared to a 96 vol.\% ethanol. The hydrogen bond between CA and tertiary amide group of PVP was confirmed. The deacetylation parameters of $\mathrm{NaOH}$ concentration, reaction time, swelling time, and solution were investigated by orthogonal experimental design (OED) method. The degree of cross-linking, the residual acetyl content, and the PVP content in the deacetylated membranes were determined by FTIR analysis. The conjoint analysis in the Statistical Product and Service Solutions (SPSS) software was used to analyze the OED results, and the importance of the deacetylation parameters was sorted as Solution $>$ Swelling time $>$ Reaction time $>$ Concentration. The optimal deacetylation condition of $96 \mathrm{vol}$ \% ethanol solution, swelling time $24 \mathrm{~h}$, the concentration of $\mathrm{NaOH}$ $(0.075 \mathrm{M})$, and the reaction time $(2 \mathrm{~h})$ were identified. The regenerated cellulose hollow fibers under the optimal deacetylation condition can be further used as precursors for preparation of hollow fiber carbon membranes.

\section{Introduction}

Carbon membranes have been studied in the last decade as a promising candidate for energy-efficient separation processes such as $\mathrm{H}_{2} / \mathrm{CH}_{4}, \mathrm{H}_{2} / \mathrm{CO}_{2}, \mathrm{CO}_{2} / \mathrm{CH}_{4}$, and Olefin/Paraffin [1]. Carbon membranes are usually prepared by the carbonization of polymer precursors, which provide better permselectivity, thermal and mechanical stability, and chemical stability compared to the commercial polymeric membranes already used [2-5]. Many literatures reported using polymeric membranes such as polyimide, PAN, and cellulosic derivatives as the precursors for making carbon membranes [6-9]. However, how to prepare cheaper, defect-free, hollow fiber precursor membranes becomes a key issue on the fabrication of carbon membranes. There are some literatures reported on the spinning of cellulose acetate (CA) fibers [1015], but those membranes were all used in the dialysis, reverse osmosis (RO), and ultrafiltration (UF) applications. Directly carbonizing CA hollow fibers to make carbon membranes is quite challenging as it will form defects on the carbon matrix or even turn into dust. However, the regenerated cellulose precursors (replace acetyl group with hydroxyl group) from CA hollow fibers can be well used to fabricate the carbon membranes. Therefore, the cellulose regeneration from CA membranes by deacetylation becomes an important step in the posttreatment of CA membranes for preparation of cellulosic based carbon membranes [16, 17]. Some literatures reported using alkali like $\mathrm{NaOH}$ and $\mathrm{KOH}$ solution for the deacetylation $[13,15,18,19]$. Liu and Hsieh reported that reaction time was very important for the deacetylation results [13]. Moreover, the deacetylation of CA membranes in $\mathrm{NaOH}$ was more efficient and complete in ethanol than in the aqueous solutions. Son et al. reported the deacetylation of CA membranes in $\mathrm{KOH}$ ethanol solution $(0.5 \mathrm{M})$ after swelling in $25 \mathrm{~mL}$ of an acetone-water mixture (V/V 1/1) for $24 \mathrm{~h}$ [15]. They found that deacetylation was very rapid and completed within $20 \mathrm{~min}$, and the deacetylated CA membranes showed the crystal structure of cellulose. The Fourier transform infrared spectroscopy (FTIR) was used in the literature to characterize the deacetylation results. However, no systematic investigation on the influences of deacetylation condition was reported, which is crucial to regenerate cellulose hollow 


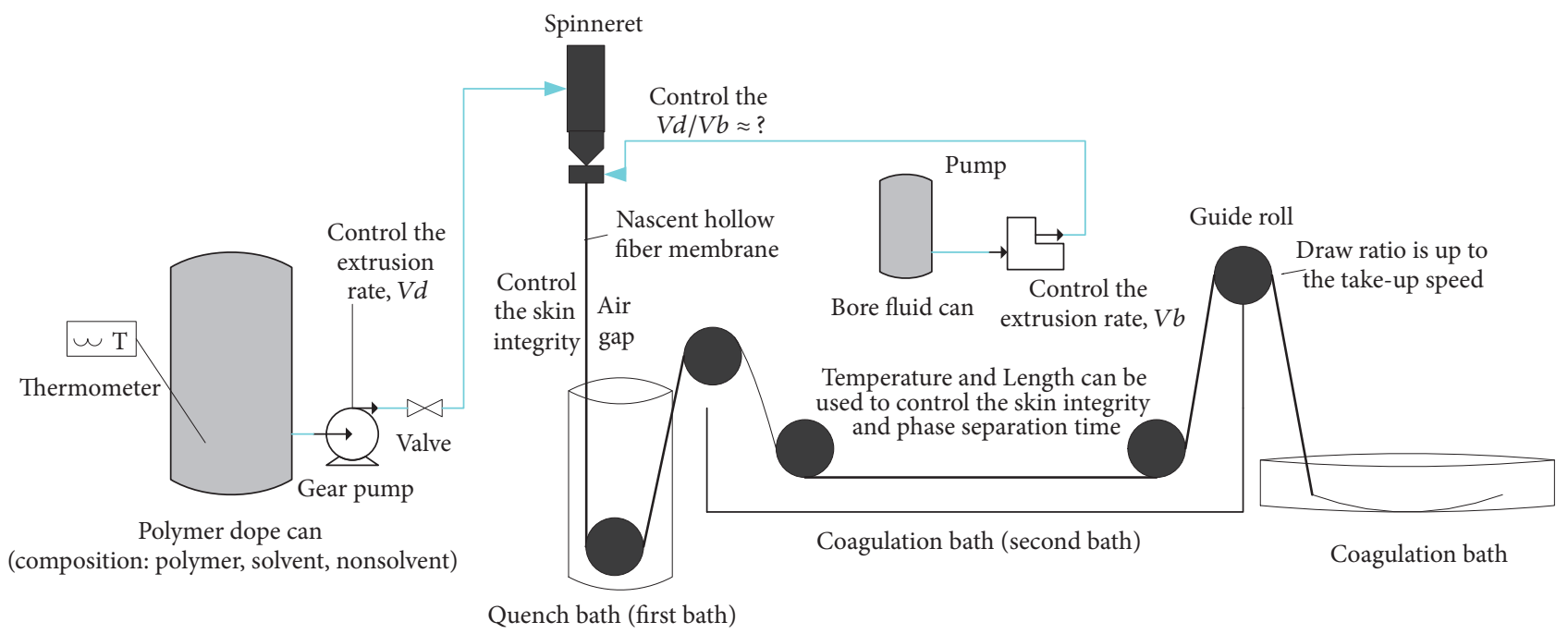

FIGURE 1: Schematic diagram of membrane spinning process.

TABLE 1: Factors and levels for OED of deacetylation.

\begin{tabular}{lcccc}
\hline Levels & Swelling time & Concentration & Solution & Reaction time \\
\hline 1 & No swelling & $0.05 \mathrm{M}$ & 96 vol.\% ethanol & $0.5 \mathrm{~h}$ \\
2 & Swelling $1 \mathrm{~h}$ & $0.075 \mathrm{M}$ & 50 vol.\% ethanol & $2 \mathrm{~h}$ \\
3 & Swelling $24 \mathrm{~h}$ & $0.1 \mathrm{M}$ & & $4 \mathrm{~h}$ \\
\hline
\end{tabular}

fibers with desired structure and property as precursors for making carbon membranes. Thus, the intention of this work was to obtain the optimal deacetylation condition based on the orthogonal experimental design (OED) method and multivariate analysis.

\section{Experimental}

2.1. Materials. CA (MW 100,000, average acetyl content: $39.8 \%$ ) was purchased from ACROS (USA). Polyvinylpyrrolidone (PVP K30, MW 10,000) was purchased from Sigma. The solvent N-methyl-2-pyrrolidone (NMP, >99.5\%) was purchased from Merck (Darmstadt, Germany). Glycerol (>98\%) was purchased from BDH/VWR. $\mathrm{NaOH}$ (>99\%) was also purchased from Merck and used in the deacetylation of CA hollow fiber membranes.

2.2. Spinning of CA Fibers. CA hollow fiber membranes were spun using a well-known dry-jet wet spinning process [14, 20]. The dope solution consists of CA, PVP, and NMP. Two gear pumps controlled the extrusion rates of dope solution and bore fluid. A double spinneret (ID/OD, 0.5/0.7 mm) was used in this study. The spun CA hollow fiber membranes were soaked in a 10 vol.\% glycerol solution overnight and then dried in the air. The additive of PVP was used to increase the porosity and make the carbon structure more open after carbonization. A schematic diagram of spinning process was shown in Figure 1.
2.3. Deacetylation. The spun CA hollow fiber membranes were deacetylated in $\mathrm{NaOH}$ solution. The deacetylation reaction of $\mathrm{CA}$ and $\mathrm{NaOH}$ is given in

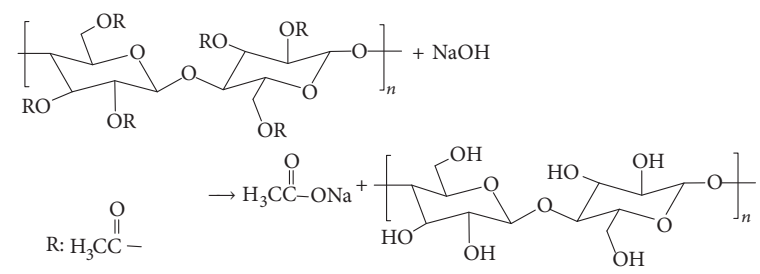

The deacetylation was initially carried out with a $0.2 \mathrm{M} \mathrm{NaOH}$ solution in 96 vol.\% ethanol at different reaction times to determine the complete deacetylation time. The $0.5 \mathrm{M} \mathrm{NaOH}$ solutions with different ethanol contents (50 vol.\% and 96 vol.\%) were then used to investigate the solution effect on the deacetylation results. The systematic investigation on the influences of the deacetylation parameters such as $\mathrm{NaOH}$ concentration, solution, deacetylation time, and swelling time on the regenerated cellulose hollow fiber properties was conducted by orthogonal experimental design (OED) method. Table 1 gives the factors and levels of the orthogonal experimental design. Moreover, two holdout experiments and two simulation cases were used for the validation of the OED's results and prediction, respectively. The IBM Statistical Product and Service Solutions (SPSS) software was used to generate the experiment plan. 


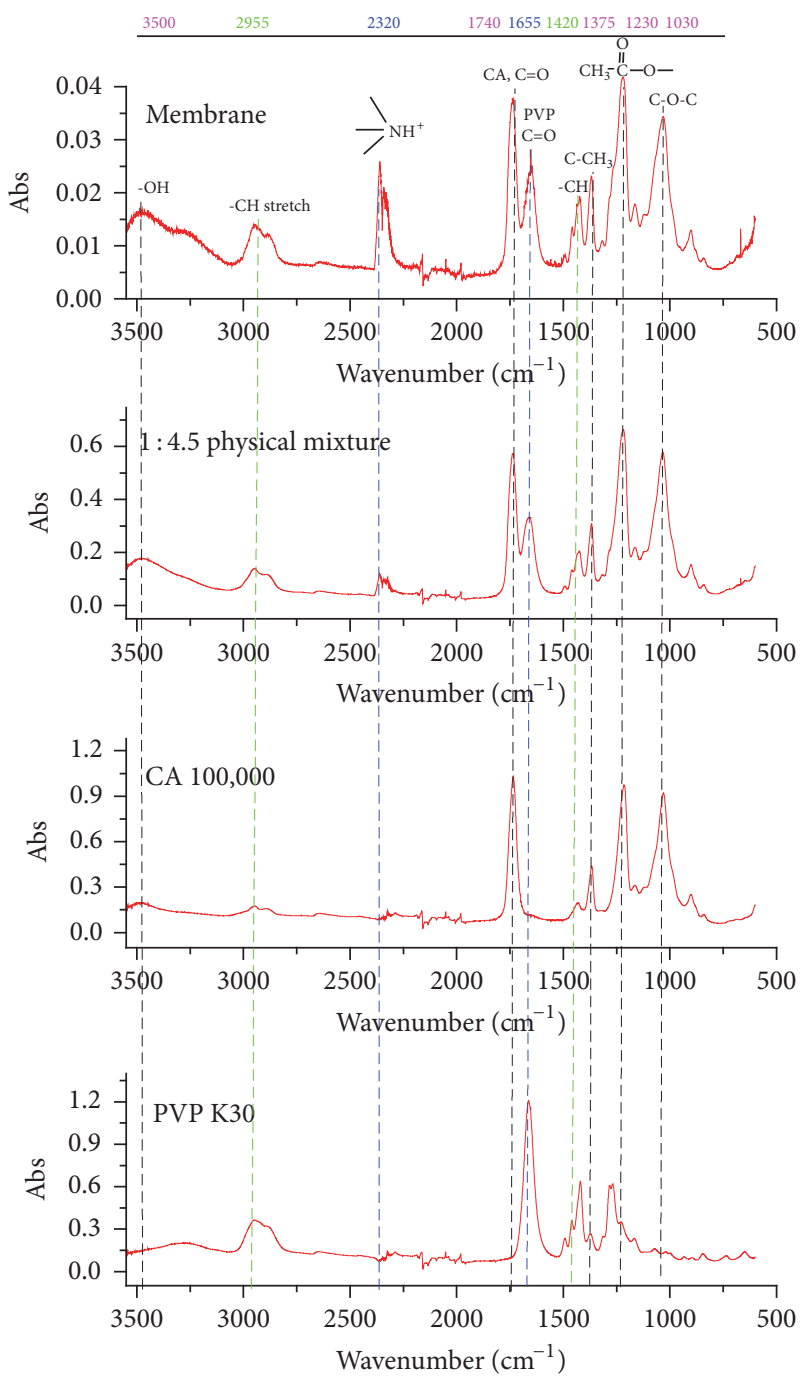

FIGURE 2: FTIR spectra of cellulose acetate and PVP.

2.4. Measurement and Characterization. Fourier transform infrared spectroscopy (FTIR) spectra for samples were obtained with Bruker Tensor 27 FTIR, which was used to determine the residual acetyl content, the PVP content, and the degree of cross-linking between CA and PVP.

\section{Results and Discussion}

3.1. Functional Group Identification by FTIR. The FTIR spectra of the pure CA, pure PVP, physical mixture of CA and PVP, and membrane are shown in Figure 2. The characteristic adsorption peaks $1030 \mathrm{~cm}^{-1}, 1230 \mathrm{~cm}^{-1}$, and $1740 \mathrm{~cm}^{-1}$ are attributed to the ether group $\left(\nu_{\mathrm{C}-\mathrm{O}-\mathrm{C}}\right)$, acetyl ester group $\left(\nu_{\mathrm{CH}_{3}-\mathrm{C}=\mathrm{O}}\right)$, and carbonyl group $\left(\nu_{\mathrm{C}=\mathrm{O}}\right)$ of $\mathrm{CA}$, respectively [15]. Moreover, the characteristic peak $1665 \mathrm{~cm}^{-1}$ is attributed to the carbonyl group of PVP.

3.2. Deacetylation of CA Hollow Fiber Membranes. The CA hollow fiber membranes spun from a CA $+\mathrm{PVP} / \mathrm{NMP} / \mathrm{H}_{2} \mathrm{O}$ dope solution were deacetylated using a $0.2 \mathrm{M} \mathrm{NaOH}$ in a 96

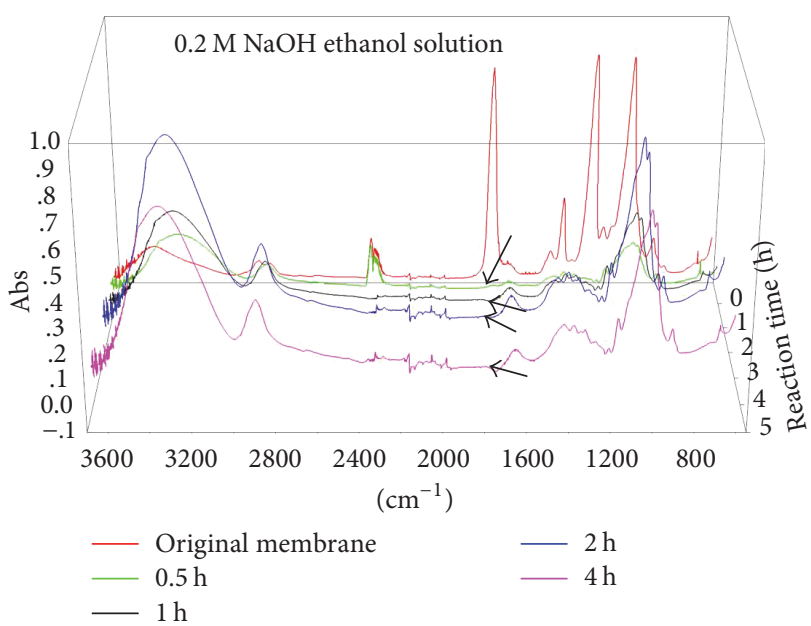

FIGURE 3: FTIR spectra for deacetylated membranes with different reaction times.

vol.\% ethanol solution at various reaction times after swelling in a $10 \mathrm{wt} . \%$ glycerol solution for $24 \mathrm{~h}$. The chemical structure changes in the CA hollow fiber membranes during deacetylation were analyzed by FTIR. Figure 3 shows the FTIR spectra results. It can be seen that the intensities of the characteristic absorption peaks attributed to the vibrations of carbonyl group at $1740 \mathrm{~cm}^{-1}\left(\nu_{\mathrm{C}=\mathrm{O}}\right)$ and $1235 \mathrm{~cm}^{-1}\left(\nu_{\mathrm{CH}_{3}-\mathrm{C}=\mathrm{O}}\right)$ decrease with the increase of reaction time, but the absorption peak at $3500 \mathrm{~cm}^{-1}\left(\nu_{\mathrm{O}-\mathrm{H}}\right)$ increases comparing to the original CA membranes. Moreover, the deacetylation reaction almost completed in half hour, which indicated that reaction rate is very fast in a high concentration $\mathrm{NaOH}$ solution.

In order to investigate the impact of ethanol solution, the deacetylation was conducted in a $0.5 \mathrm{M} \mathrm{NaOH}$ in 50 vol.\% and 96 vol.\% ethanol solutions with different reaction times. The FTIR was used to determine the residual acetyl content after deacetylation. Figure 4 shows the relationship between the residual acetyl content in the CA hollow fiber membranes and reaction time at different ethanol solutions. It can be found that reaction rate in a 50 vol.\% ethanol solution was faster compared to that in a 96 vol.\% ethanol solution. The significant influence of ethanol solution was found at a short reaction time $(<2 \mathrm{~h})$.

The above results in Figures 3 and 4 indicated that the concentration of $\mathrm{NaOH}$, swelling time, solution (i.e., different ethanol content), and reaction time had significant influences on the deacetylation results. The systematical investigation and identification of the optimal deacetylation condition are essential to fabricate the regenerated cellulose precursors with desired properties for making carbon membrane. Thus, the orthogonal experimental design method was introduced to optimize the deacetylation conditions in this study. Table 2 gives the OED's results for deacetylation of CA hollow fiber membranes. FTIR was used to characterize the deacetylation results. Figure 5 shows the FTIR spectra of the OED results for deacetylation. The additional hydrogen bond was formed between the CA and tertiary amide group of PVP based on the strong absorption bands in the 


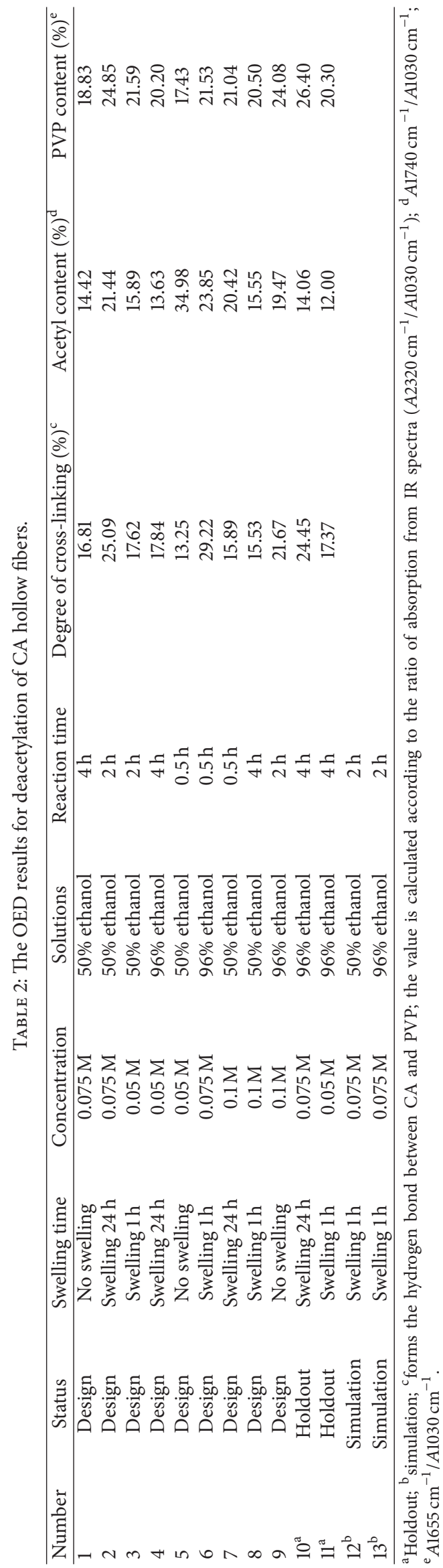




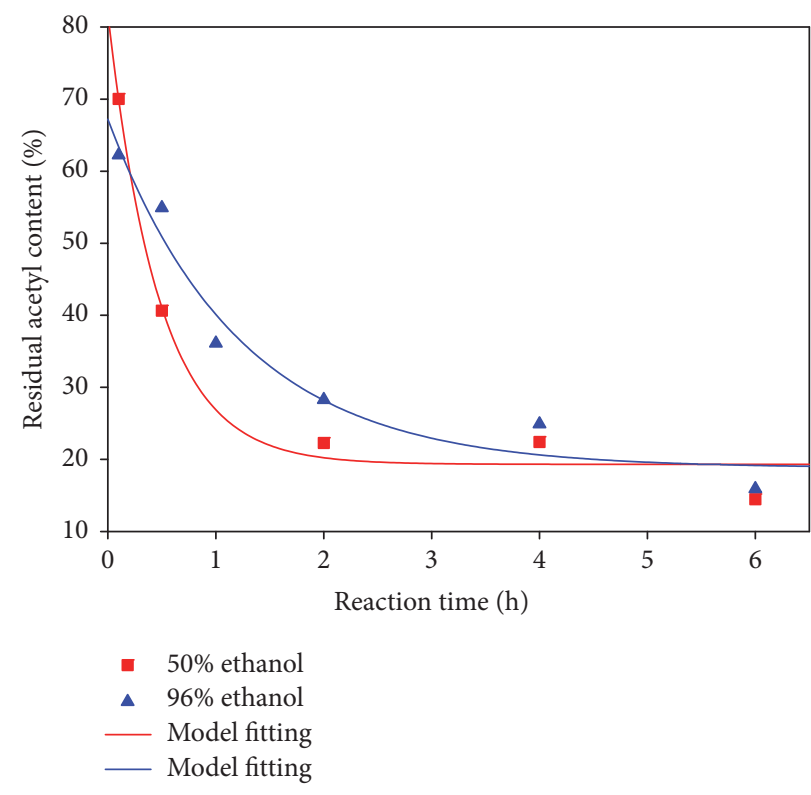

FIGURE 4: Dependence of residual acetyl content in membranes on reaction time.

region of $2250-2700 \mathrm{~cm}^{-1}$ which is attributed to the characteristics of hydrogen bond of tertiary amide [21]. It is speculated that the formation of hydrogen bond between CA and PVP is represented in Figure 6. Therefore, the absorption ratios $A 2320 \mathrm{~cm}^{-1} / A 1030 \mathrm{~cm}^{-1}$ could be used to estimate the degree of cross-linking (hydrogen bond) of the deacetylated membranes. Moreover, the absorption ratios of $A 1740 \mathrm{~cm}^{-1} / A 1030 \mathrm{~cm}^{-1}$ and $A 1665 \mathrm{~cm}^{-1} / A 1030 \mathrm{~cm}^{-1}$ from FTIR spectra in Figure 5 were used to estimate the residual acetyl content and PVP content in the membranes, respectively.

3.2.1. Conjoint Analysis. The conjoint analysis [22] in the SPSS package was used to analyze the results of orthogonal experimental design by estimation of the part worthy of the contribution from each factor's level. Three indexes of degree of cross-linking, residual acetyl content, and PVP content in the deacetylated CA hollow fiber membranes were used to analyze the deacetylation results. The basic theory of conjoint analysis has been reported in the previous work [17]. The importance for each factor was calculated separately for each subject, and then averaged. The correlations of Pearson's $R$ and Kendall's tau are 0.989 and 0.914 , respectively, which indicated a good consistency between the estimated preferences and experimental results. Table 3 shows the utilities (part-worth) of each factor level and averaged importance scores for all factors. Higher utility values indicate greater preference. As expected, there is a positive relationship between the swelling time and utility (larger negative values with short swelling time mean lower utility). All the utilities are expressed in a common unit and can be added to give the total utility for any combination. Table 4 gives a simple comparison for the combinations of an arbitrary factor level (case 1) and the optimal deacetylation condition (case 2).
TABLE 3: Utilities and averaged importance scores for different factors.

\begin{tabular}{lcc}
\hline Factors and levels & Utility estimate & $\begin{array}{c}\text { Averaged } \\
\text { importance } \\
\text { score }(\%)\end{array}$ \\
\hline Swelling time & -0.889 & \\
No swelling & -0.667 & 31.94 \\
Swelling for 1h & 1.556 & \\
Swelling for 24h & & \\
Concentration & 0.222 & \\
$0.05 \mathrm{M}$ & 0.333 & \\
$0.075 \mathrm{M}$ & -0.556 & 34.36 \\
$0.1 \mathrm{M}$ & & \\
Solution & -1.500 & \\
$50 \%$ ethanol & 1.500 & \\
$96 \%$ ethanol & & \\
Reaction time & 0.111 & \\
$0.5 \mathrm{~h}$ & -0.111 & \\
$2 \mathrm{~h}$ & 5.500 & \\
$4 \mathrm{~h}$ & & \\
(Constant) & & \\
\hline
\end{tabular}

The averaged importance scores were used to characterize the significance of the individual factor to the overall preference. The factors with higher averaged importance score (e.g., Solution) play a more significant role compared to those with low score (e.g., $\mathrm{NaOH}$ concentration) as shown in Table 3. Thus, the importance for these spinning parameters was sorted as

Solution $>$ Swelling time $>$ Reaction time $>$ Concentration.

The selection of solution greatly affects the deacetylation results, and the importance of $\mathrm{NaOH}$ concentration in this range is relatively small. This result can be used to guide the further experimental investigation on the deacetylation of CA hollow fiber membranes, and the deacetylated membrane will be used to make carbon membrane subsequently.

3.2.2. Predictions. The real power of conjoint analysis is the ability to predict the conditions that were not rated by the subjects. Based on the conjoint analysis results of orthogonal experimental design, one can predict the property of regenerated cellulose hollow fibers under other deacetylation conditions which have not been included in the plan and the holdout runs referred to the simulation cases in Table 2. The prediction results were shown in Table 5. Across the three subjects (i.e., acetyl content, PVP content, and degree of cross-linking) in this study, the three models using Maximum utility, BTL, and Logit indicated that simulation case 2 would be preferred. In order to validate this simulation result, the deacetylation experiments under these two conditions were carried out and characterized by FTIR. The FTIR 


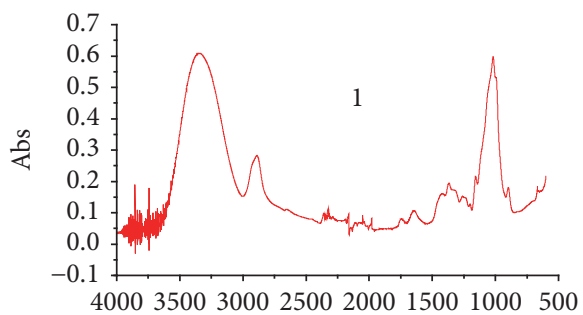

$\left(\mathrm{cm}^{-1}\right)$

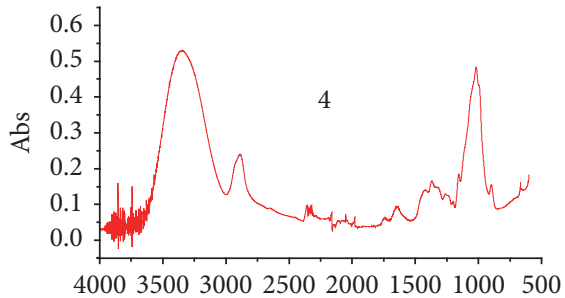

$\left(\mathrm{cm}^{-1}\right)$

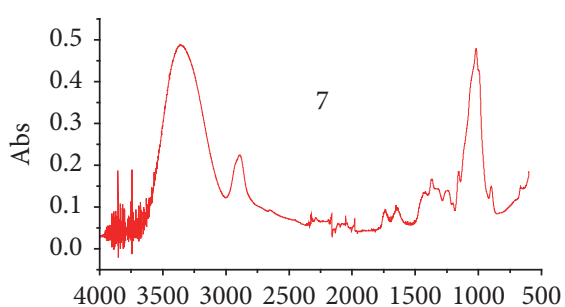

$\left(\mathrm{cm}^{-1}\right)$

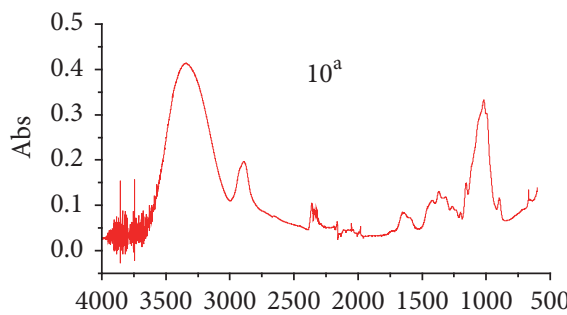

$\left(\mathrm{cm}^{-1}\right)$

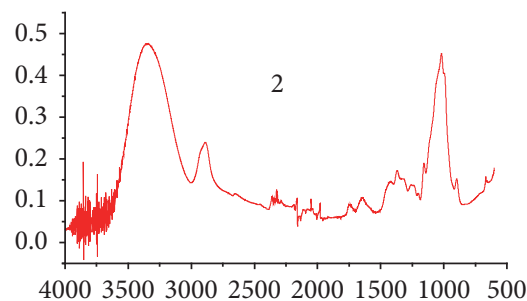

$\left(\mathrm{cm}^{-1}\right)$

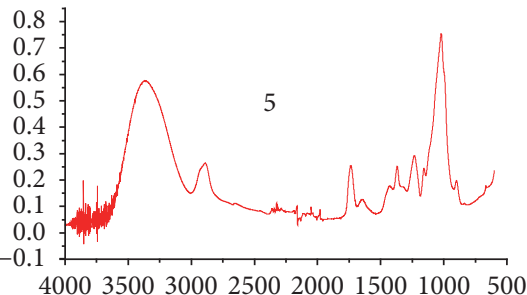

$\left(\mathrm{cm}^{-1}\right)$

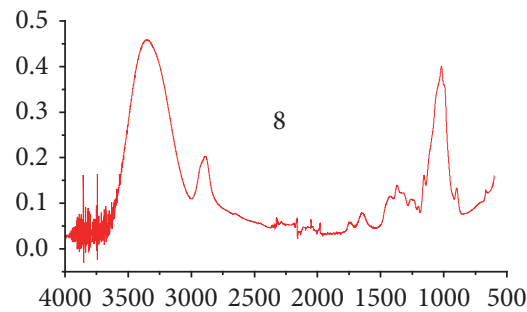

$\left(\mathrm{cm}^{-1}\right)$

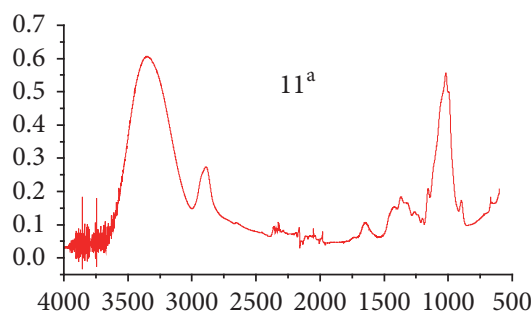

$\left(\mathrm{cm}^{-1}\right)$

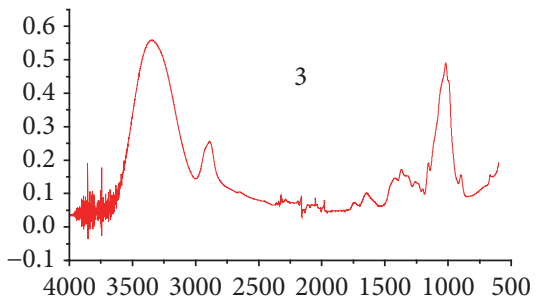

$\left(\mathrm{cm}^{-1}\right)$

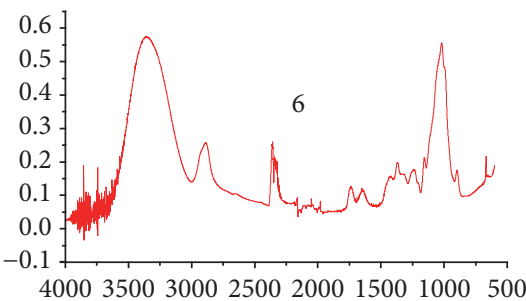

$\left(\mathrm{cm}^{-1}\right)$

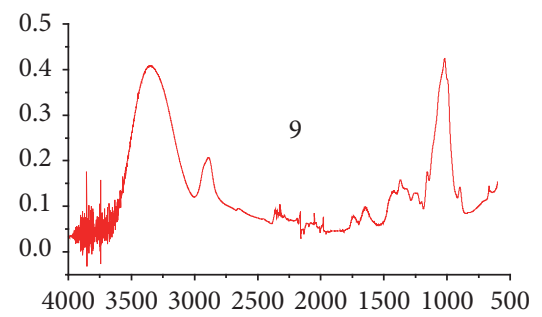

$\left(\mathrm{cm}^{-1}\right)$

FIGURE 5: FTIR spectra of deacetylated membranes (refer to Table 2).

TABLE 4: The examples of different deacetylation conditions.

\begin{tabular}{lcccccc}
\hline Case & $\begin{array}{c}\text { Utility } \\
\text { (swelling } \\
\text { time })\end{array}$ & $\begin{array}{c}\text { Utility } \\
\text { (concentration) }\end{array}$ & $\begin{array}{c}\text { Utility } \\
\text { (solution) }\end{array}$ & $\begin{array}{c}\text { Utility } \\
\text { (reaction } \\
\text { time) }\end{array}$ & $\begin{array}{c}\text { Utility } \\
\text { (constant) }\end{array}$ & $\begin{array}{c}\text { Total } \\
\text { utility }\end{array}$ \\
\hline 1 & $\begin{array}{c}\text { No swelling } \\
(-0.889)\end{array}$ & $0.05(0.222)$ & $\begin{array}{c}50 \% \text { ethanol } \\
(-1.5)\end{array}$ & $0.5 \mathrm{~h}(0)$ & 5.500 & 3.333 \\
2 & $\begin{array}{c}\text { Swelling } 24 \mathrm{~h} \\
(1.556)\end{array}$ & $0.075(0.333)$ & $\begin{array}{c}96 \% \text { ethanol } \\
(1.5)\end{array}$ & $2 \mathrm{~h}(0.111)$ & 5.500 & 9 \\
\hline
\end{tabular}

TABLE 5: Simulation results by conjoint analysis.

\begin{tabular}{lcccc}
\hline $\begin{array}{l}\text { Card } \\
\text { number }\end{array}$ & Score & $\begin{array}{c}\text { Maximum } \\
\text { utility }\end{array}$ & BTL & Logit \\
\hline 1 & 3.778 & $.0 \%$ & $35.9 \%$ & $6.9 \%$ \\
2 & 6.778 & $100.0 \%$ & $64.1 \%$ & $93.1 \%$ \\
\hline
\end{tabular}

spectra in Figure 7 showed that the degree of cross-linking $\left(A 2320 \mathrm{~cm}^{-1} / A 1030 \mathrm{~cm}^{-1}\right)$ is weaker and the residual acetyl content $\left(A 1740 \mathrm{~cm}^{-1} / A 1030 \mathrm{~cm}^{-1}\right)$ is less in case 2 , and the PVP content $\left(A 1665 \mathrm{~cm}^{-1} / A 1030 \mathrm{~cm}^{-1}\right)$ is almost the same. It indicated that deacetylation condition of case 2 is better, which keeps the consistency with the simulation results by the 


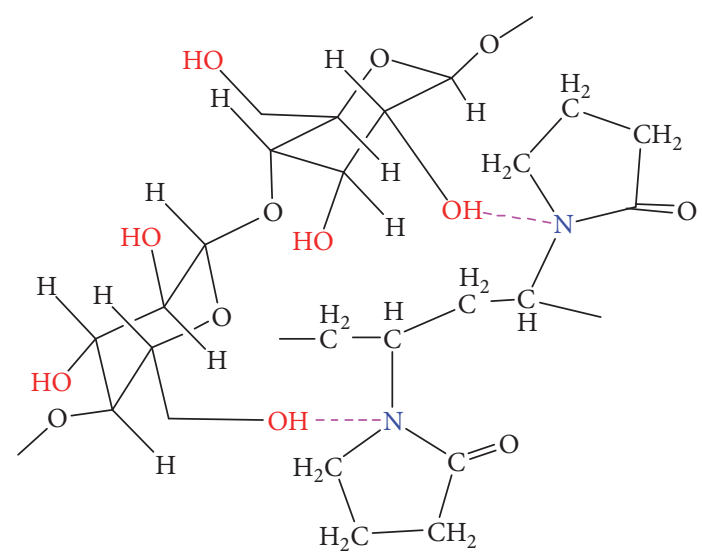

FIGURE 6: Structure of hydrogen bond between CA and PVP.
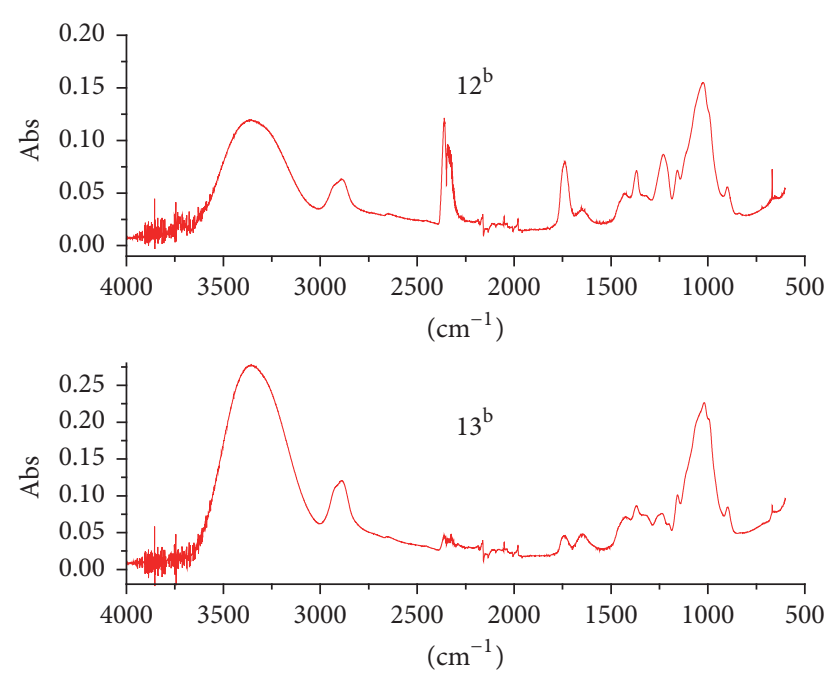

FIgURE 7: FTIR spectra of the simulation cases (refer to Table 2).

conjoint analysis. Therefore, the prediction results based on conjoint analysis can be well used to guide the experimental design.

\section{Conclusions}

CA hollow fiber membranes were spun from a dope solution containing $\mathrm{CA} / \mathrm{PVP} / \mathrm{NMP} / \mathrm{H}_{2} \mathrm{O}$ using a dry-jet wet spinning process. The deacetylation of spun CA hollow fiber membranes was carried out in $\mathrm{NaOH}$ solutions. The reaction rate was very fast and completed within $0.5 \mathrm{~h}$ using high concentration $(0.2 \mathrm{M}) \mathrm{NaOH}$ ethanol (96 vol.\%) solutions. Moreover, the reaction rate is much quicker in the $\mathrm{NaOH}$ ethanol (50\%) solution compared to the $\mathrm{NaOH}$ ethanol (96 vol.\%) solution. From the FTIR spectra of the deacetylated membranes, the formation of hydrogen bond between CA and tertiary amide group of PVP was found. Four factors of concentration of $\mathrm{NaOH}$, reaction time, swelling time, and solution were systematically investigated based on the OED method, and the conjoint analysis results indicated that the importance of these factors is

Solution $>$ Swelling time $>$ Reaction time $>$ Concentration.

The optimal deacetylation condition with a 96 vol.\% ethanol solution, a swelling time $24 \mathrm{~h}$, a $0.075 \mathrm{M} \mathrm{NaOH}$ solution, and a reaction time of $2 \mathrm{~h}$ was identified. The regenerated cellulose hollow fibers under the optimal deacetylation condition can be used as precursors for fabrication of carbon membrane subsequently.

\section{Conflicts of Interest}

The author declares that there are no conflicts of interest regarding the publication of this paper.

\section{Acknowledgments}

The author would like to acknowledge the Research Council of Norway for funding this work under the CO2Hing Project (\#267615).

\section{References}

[1] J. A. Lie, X. He, I. Kumakiri, H. Kita, and M.-B. Hagg, "Carbonbased membranes," in Hydrogen Production, Separation and Purification for Energy, A. B. Basile, F. D. Dalena, J. T. Jianhua Tong, and T. N. Vezirolu, Eds., pp. 405-431, Institution of Engineering and Technology, 2017.

[2] J. N. Barsema, Carbon membranes precursor, preparation and functionalization [Ph.D. thesis], University of Twente, Enschede, Netherlands, 2007.

[3] E. P. Favvas, G. C. Kapantaidakis, J. W. Nolan, A. C. Mitropoulos, and N. K. Kanellopoulos, "Preparation, characterization and gas permeation properties of carbon hollow fiber membranes based on Matrimid ${ }^{\circledR} 5218$ precursor," Journal of Materials Processing Technology, vol. 186, no. 1-3, pp. 102-110, 2007.

[4] J. A. Lie, Synthesis, performance and regeneration of carbon membranes for biogas upgrading-a future energy carrier [Ph.D. thesis], Norwegian University of Science and Technology, Trondheim, Norway, 2005.

[5] S. M. Saufi and A. F. Ismail, "Development and characterization of polyacrylonitrile (PAN) based carbon hollow fiber membrane," Songklanakarin Journal of Science and Technollogy, vol. 24, pp. 843-854, 2002.

[6] L. I. B. David and A. F. Ismail, "Influence of the thermastabilization process and soak time during pyrolysis process on the polyacrylonitrile carbon membranes for $\mathrm{O}_{2} / \mathrm{N}_{2}$ separation," Journal of Membrane Science, vol. 213, no. 1-2, pp. 285-291, 2003.

[7] H. Zhang, J. Wu, J. Zhang, and J. He, "1-Allyl-3-methylimidazolium chloride room temperature ionic liquid: a new and powerful nonderivatizing solvent for cellulose," Macromolecules, vol. 38, no. 20, pp. 8272-8277, 2005.

[8] A. Soffer, J. Koresh, and S. Saggy, "Separation device," US patent 4685940, 1987.

[9] D. Q. Vu, W. J. Koros, and S. J. Miller, "High pressure $\mathrm{CO}_{2} / \mathrm{CH}_{4}$ separation using carbon molecular sieve hollow fiber membranes," Industrial \& Engineering Chemistry Research, vol. 41, no. 3, pp. 367-380, 2002. 
[10] K. J. Edgar, C. M. Buchanan, J. S. Debenham et al., "Advances in cellulose ester performance and application," Progress in Polymer Science, vol. 26, no. 9, pp. 1605-1688, 2001.

[11] J.-H. Hao, H.-P. Dai, P.-C. Yang, J.-M. Wei, and Z. Wang, “Cellulose acetate hollow fiber performance for ultra-low pressure reverse osmosis," Desalination, vol. 107, no. 3, pp. 217-221, 1996.

[12] X. Jie, Y. Cao, J.-J. Qin, J. Liu, and Q. Yuan, "Influence of drying method on morphology and properties of asymmetric cellulose hollow fiber membrane," Journal of Membrane Science, vol. 246, no. 2, pp. 157-165, 2005.

[13] H. Liu and Y.-L. Hsieh, "Ultrafine fibrous cellulose membranes from electrospinning of cellulose acetate," Journal of Polymer Science B: Polymer Physics, vol. 40, no. 18, pp. 2119-2129, 2002.

[14] J.-J. Qin, Y. Li, L.-S. Lee, and H. Lee, "Cellulose acetate hollow fiber ultrafiltration membranes made from CA/PVP 360 K/NMP/water," Journal of Membrane Science, vol. 218, no. 1-2, pp. 173-183, 2003.

[15] W. K. Son, J. H. Youk, T. S. Lee, and W. H. Park, "Electrospinning of ultrafine cellulose acetate fibers: studies of a new solvent system and deacetylation of ultrafine cellulose acetate fibers," Journal of Polymer Science, Part B: Polymer Physics, vol. 42, no. 1, pp. 5-11, 2004.

[16] X. He, J. A. Lie, E. Sheridan, and M.-B. Hagg, "Preparation and characterization of hollow fiber carbon membranes from cellulose acetate precursors," Industrial and Engineering Chemistry Research, vol. 50, no. 4, pp. 2080-2087, 2011.

[17] X. He and M.-B. Hägg, "Optimization of carbonization process for preparation of high performance hollow fiber carbon membranes," Industrial and Engineering Chemistry Research, vol. 50, no. 13, pp. 8065-8072, 2011.

[18] N. Olaru and L. Olaru, "Cellulose acetate deacetylation in benzene/acetic acid/water systems," Journal of Applied Polymer Science, vol. 94, no. 5, pp. 1965-1968, 2004.

[19] Y. Yamashita and T. Endo, "Deterioration behavior of cellulose acetate films in acidic or basic aqueous solutions," Journal of Applied Polymer Science, vol. 91, no. 5, pp. 3354-3361, 2004.

[20] J.-J. Qin, F.-S. Wong, Y. Li, and Y.-T. Liu, "A high flux ultrafiltration membrane spun from PSU/PVP (K90)/DMF/1,2propanediol," Journal of Membrane Science, vol. 211, no. 1, pp. 139-147, 2003.

[21] R. P. Swatloski, S. K. Spear, J. D. Holbrey, and R. D. Rogers, "Dissolution of cellose with ionic liquids," Journal of the American Chemical Society, vol. 124, no. 18, pp. 4974-4975, 2002.

[22] SPSS Conjoint ${ }^{\mathrm{TM}}$ 17.0, 2009, https://www.washington.edu/ uware/spss/docs/SPSSConjoint17.0.pdf. 

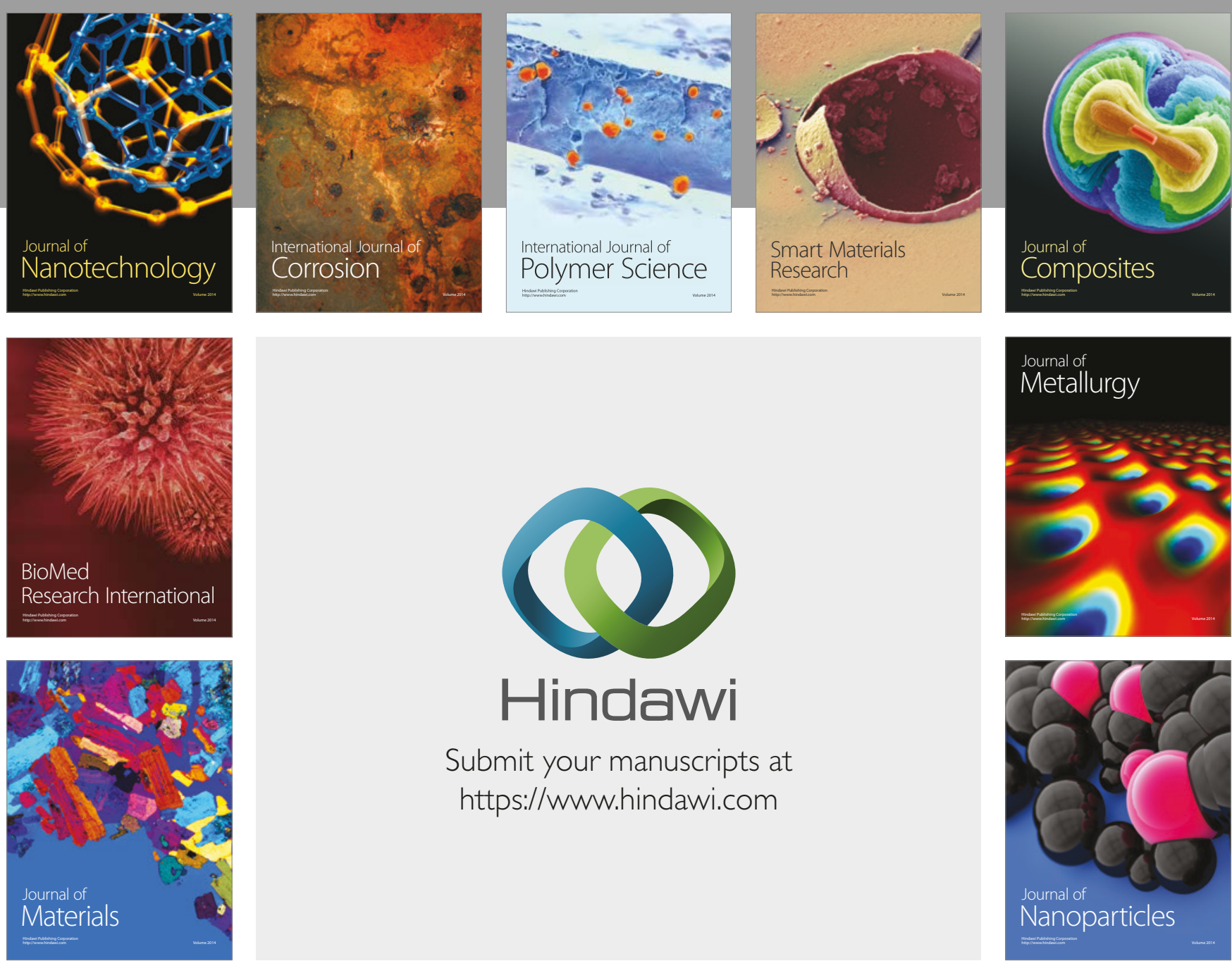

\section{Hindawi}

Submit your manuscripts at

https://www.hindawi.com
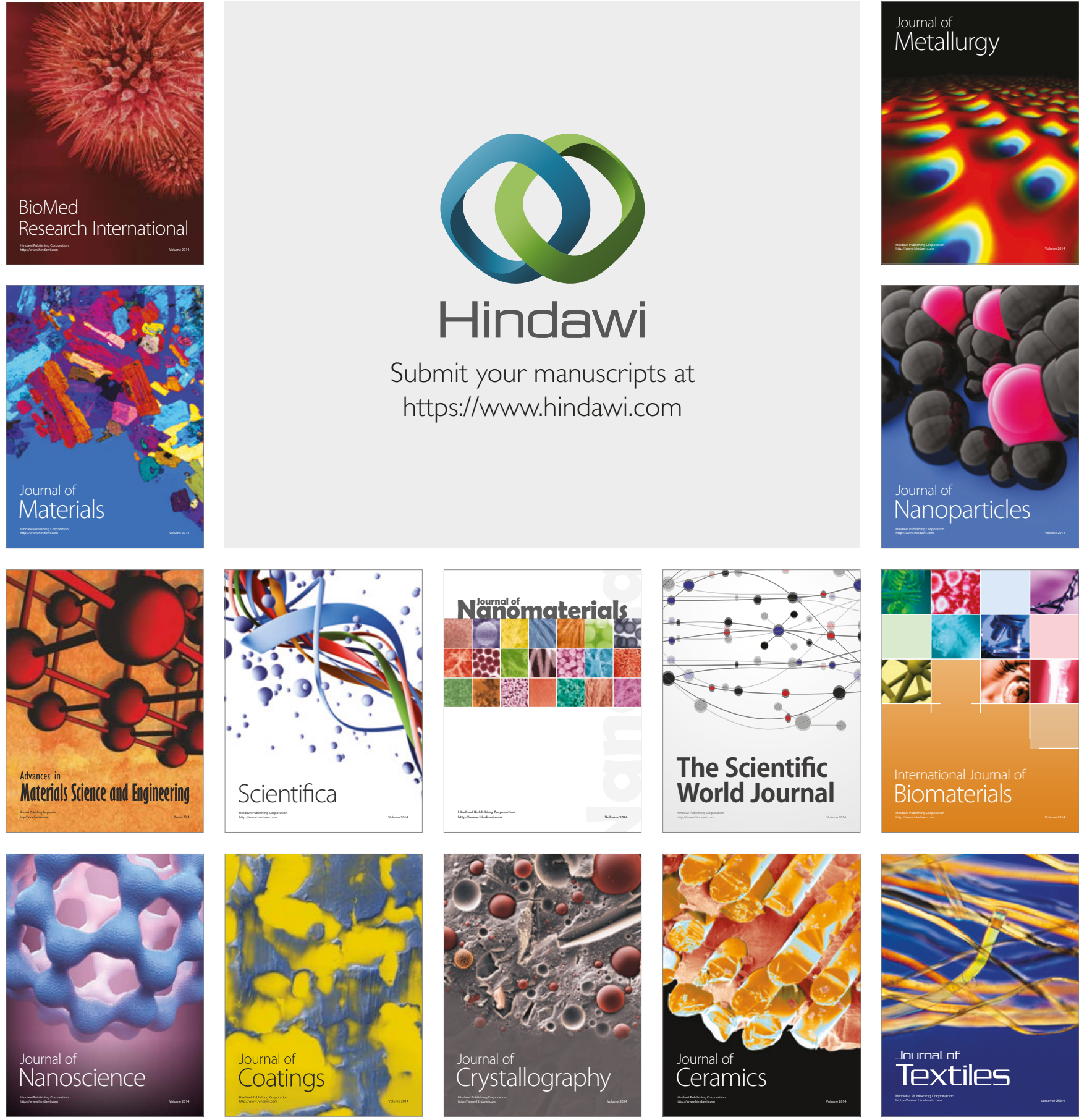

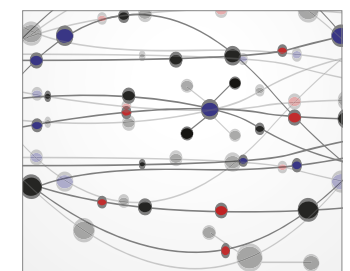

The Scientific World Journal
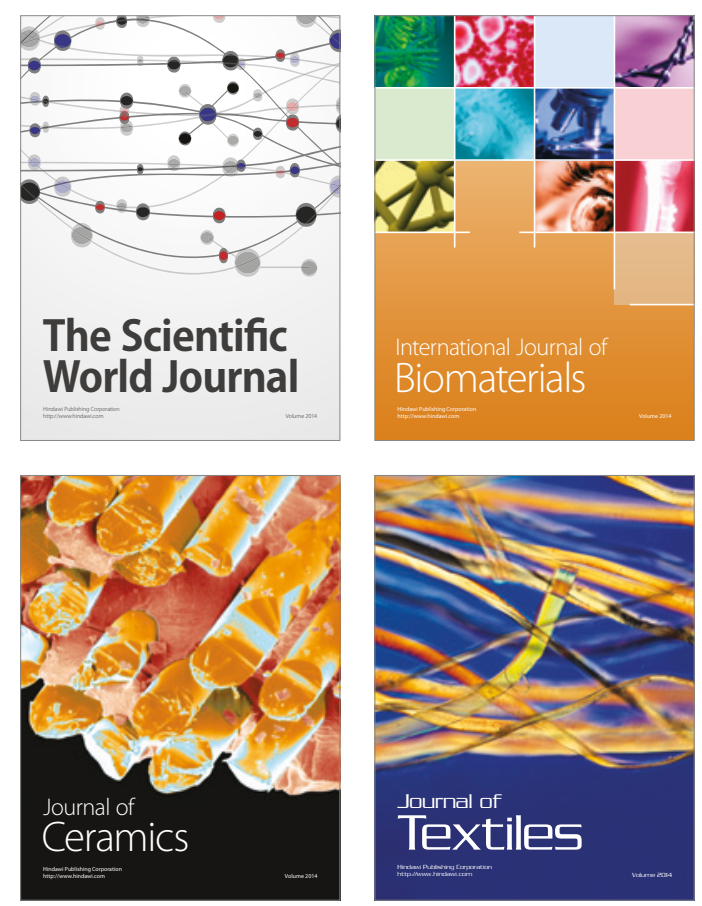